\title{
Lives in many Hands: The Medical Landscape in Lancashire, 1700-1820
}

\author{
STEVEN KING and ALAN WEAVER*
}

Medical historians over the last two decades have provided a basic overview of the development of the medical market-place, doctoring, diagnosis and treatment, doctor-patient relationships, and the nature and longevity of alternative medical practices. They have suggested that doctors were almost always the last port of call for most families confronting everyday illness, either because of cost, availability, or preference in the light of the limitations of medical diagnosis and treatment. ${ }^{1}$ Equally, it has been suggested that self-medication was common among middling and other families in the past, that "old wives" and irregular practitioners had a considerable longevity in the medical patchwork, and that "quackery" exploded in urban areas in particular during the later eighteenth century. ${ }^{2}$ The struggle by doctors to distance themselves both from their own patients (through new medical language and forms of diagnosis) and from other parts of the calling, such as apothecaries, has been well documented. ${ }^{3}$ So has the long-running conflict, in the spheres of diagnosis and treatment, between established medical theory on the one hand and empiricism on the other. ${ }^{4}$

These sorts of broad-brush generalizations have proved invaluable to the development of the social history of medicine. They also act as a limitation, fostering a concentration on "medical development" at the national level, and serving to deflect attention from the observation and explanation of regional and local differences in the development of medicine as a trade and in the consumption of medicine by

* Dr Steven King and Mr Alan Weaver, The
School of Humanities, Oxford Brookes
University, Gypsy Lane Campus, Headington,
Oxford OX3 0BP.

Our thanks are due to the four referees of this paper, who provided valuable commentary and a number of new perspectives. Also to the Scouloudie Foundation for their support of some of the research outlined in this article.

\footnotetext{
${ }^{1}$ For just some of many examples, see $\mathrm{L}$ M Beier, 'In sickness and in health: a seventeenth century family experience', in R Porter (ed.), Patients and practitioners: lay perceptions of medicine and pre-industrial society, Cambridge University Press, 1985, pp. 108-28, and A Wear, 'Puritan perceptions of illness in seventeenthcentury England', in ibid., pp. 55-99. For later examples, see W F Bynum and R Porter (eds),
}

\footnotetext{
Medical fringe and medical orthodoxy 1750-1850, London, Croom Helm, 1987, pp. 29-39.

${ }^{2} \mathrm{G}$ Smith, 'Prescribing the rules of health: self-help and advice in the later eighteenth century', in Porter (ed.), op. cit., note 1 above, pp. 249-82, and R Porter, Health for sale: quackery in England 1660-1850, Manchester University Press, 1989. See also J Obelkevich, Religion and rural society: South Lindsey 1825-1875, Oxford, Clarendon Press, 1976.

${ }^{3}$ See M Fissell, 'The disappearance of the patients' narrative and the invention of hospital medicine', in R French and A Wear (eds), British medicine in an age of reform, London, Routledge, 1991, pp. 92-109.

${ }^{4}$ See J Cule, 'The Rev. John Wesley, M.A. (Oxon.), 1703-1791: "The naked empiricist" and orthodox medicine', Bull. Hist. Med., 1990, 45: 41-63.
} 


\section{Steven King and Alan Weaver}

patients. Some important work has been done. The southwest, particularly the Bristol area, has been the subject of a number of studies. ${ }^{5}$ London has also been the focus of much empirical work, while Anne Digby has provided a broad regional overview of the development of the doctoring trade over almost two centuries. ${ }^{6}$ However, systematic regional analyses of the medical landscape and attitudes to medicine on the part of consumers are notable by their absence.

To some extent, of course, the failure to develop a detailed regional focus is not surprising. Identifying a "region" or even a "community" is by no means an easy task. ${ }^{8}$ Even if this were not a problem, the vagaries of source survival mean that in some places there is not enough material to characterize the local medical landscape, while in others material is simply too voluminous to handle easily. Where source material does survive, medical historians face two thorny interpretative problems. First, when discussing chronological changes in the texture of the medical fabric at local and regional levels and relating them to the attitudes of doctors and patients, they have to make a distinction between the outcome of "choice" on the part of consumers and professionals, and the outcome of "constraints" imposed by wider socio-economic, demographic and other changes. Such constraints were wide ranging. Population growth and urban-industrial development in the later eighteenth century altered the profile of disease which middling families faced. Changes in fashion, the nature of the domestic environment, the character of sociability, transport and postal systems, the means by which female authority was constructed and maintained at local level, as well as in the way doctors made a living (and hence their accessibility) may all have imposed limitations on the extent and character of the local medical scene irrespective of the active choices of patient and professional. ${ }^{9}$ A second, and related, problem lies in interpreting how far local and regional peculiarities reflect real, enduring, and conscious attitudes towards medicine and medical personnel, and how far they simply reveal different stages of adjustment to wider changes in medical theory and practice. There is a danger that the only outcome of detailed and

\footnotetext{
${ }^{5}$ See J Barry, 'Publicity and the public good: presenting medicine in eighteenth-century Bristol', in Bynum and Porter (eds), op. cit., note 1 above, pp. 29-39, for a review of extensive work on the Bristol-Bath area.

${ }^{6}$ See French and Wear, op. cit., note 3 above, and A Digby, Making a medical living: doctors and patients in the English market for medicine, 1720-1911, Cambridge University Press, 1994.

${ }^{7}$ See discussion of the place of such work in $\mathrm{R}$ Porter, 'The patient's view: doing medical history from below', Theory and Society, 1985, 14: 175-98.

${ }^{8}$ For an exhaustive discussion of this point see the contributions to S Brakensieck and A Flugel (eds), Regionalgeschichte in Europa: gemeinsame probleme, interdisziplinaire ansatze, nationale traditionen, Bielefeld, Scott, 1999.

${ }^{9}$ For more on external constraints, see J Barry and C Brooks (eds), The middling sort of people: culture, society and politics in England, 1550-1800,
}

London, Macmillan, 1994; P Griffiths, A Fox and $\mathrm{S}$ Hindle (eds), The experience of authority in early modern England, London, Macmillan, 1996. The issue of the economics of doctoring has been explored in Digby, op. cit., note 6 above, but there have been few investigations of the wider economic circumstances of doctors. In Cumbria some of the most prominent antiquarian historians of the nineteenth-century were medical men who thus supplemented their limited income from doctoring and increased their local visibility. Changes in the nature of occupations, with widespread trends towards occupational concentration rather than pluralism, may also have restricted the availability of irregular practitioners. See I Loudon, 'Medical practitioners $1780-1850$ and the period of medical reform in Britain', in A Wear (ed.), Medicine in society: historical essays, Cambridge University Press, 1992, pp. 219-47. 
time-consuming local and regional analysis will be confirmation of well-established "national" generalizations.

These caveats are, of course, important. However, they can also be overplayed, and there may be scope for a new model of the character of local medical practice. One might argue, for instance, that regional and local medical cultures are worth investigating in their own right. The very process of recovering them from history provides a valuable lesson in the linkage and interpretation of multiple sources for a medical history literature which has sometimes ignored the question of methodology. One could also go further, and suggest that detailed analysis of the "grassroots world of healing" might allow us to fill some of the gaps which are left in painting the broad picture. A framework of regional studies would provide a buttress against claims that "national" generalizations on a range of issues are based upon a raft of unexplored assumptions about the character and vibrancy of medical culture at local and regional level, and about how this culture changed over time. The gaps in our current knowledge are certainly easy to find. For example, if self-medication was ubiquitous, we still know little about its detailed character. ${ }^{10}$ If we know ever more about formal doctoring, we still know comparatively little about the middling families who were the patients. ${ }^{11}$ The broad outlines of the components of medical provision upon which people could draw are clear, but the reasons why they combined different constellations of medical provision at different times, and finally turned to a doctor, still require substantive discussion. This is particularly the case for the eighteenthcentury. Yet systematic regional and local studies can also do more than simply fill gaps. On the one hand, they can provide a vehicle for questioning the implicit theoretical models (rational consumption, "progress", market clearing) which underpin some medical historiography. ${ }^{12}$ On the other, they can suggest new strands of motivation, belief, and experience which might otherwise remain buried, providing an historical foundation for understanding the enduring regional and local disparities in health, doctor-patient ratios, and mortality which characterized the period between 1700 and 1900. Indeed, to appreciate the potential of a framework of regional studies for modifying and undermining national generalizations, one needs to look no further than recent developments in historical demography. ${ }^{13}$

These perspectives on the value of detailed local work underpin the systematic

\footnotetext{
${ }^{10}$ However, see R Porter, 'Laymen doctors and medical knowledge in the eighteenth century: the evidence of the Gentleman's Magazine', in Porter, op. cit., note 1 above, pp. 283-314, and M Chamberlain, Old wives' tales: their history, remedies, and spells, London, Virago, 1981.

"See J Lane, " "The doctor scolds me": the diaries and correspondence of patients in eighteenth century England', in Porter, op. cit., note 1, pp. 205-48, and Porter, op. cit., note 7 above.

${ }^{12}$ We are grateful to one of the referees who pointed out that much of the economic theory which must lie behind a medical marketplace model is poorly specified by medical historians. By rational consumption, we mean a situation in
}

\author{
which consumers react to the falling price or \\ increased availability of medical services by \\ demanding more of an "obvious good". By \\ market clearing we mean a situation in which \\ more people would train or practitioners would \\ physically move to meet latent demand for \\ medical services. By the same token, inadequate \\ demand should lead to a rapid adjustment in the \\ number of practitioners in a locality. \\ ${ }^{13}$ For a review of these developments, see S A \\ King, 'English historical demography and the \\ nuptiality conundrum: new perspectives', Hist. \\ soc. Res., 1998, 23: 130-56, and E A Wrigley, R S \\ Davies, J E Oeppen and R S Schofield, English \\ population history from family reconstitution, \\ 1580-1837, Cambridge University Press, 1997.
}




\section{Steven King and Alan Weaver}

regional study attempted here. Our article concentrates on exploring the landscape of medical care as it would have looked to middling and elite families in rural and small town Lancashire during the long eighteenth century, and particularly after $1750 .{ }^{14}$ Reviewing the previously unused records of a number of Lancashire doctors, it contends that we can identify complex sub-regional variations in the role and character of formal doctoring, and that theoretical notions of supply and demand, market clearing, and rationality, come off badly when set against deep rooted cultural norms and enduring localized patterns of alternative care and healing structures. In some areas, recourse to these structures appears to have been tantamount to a rejection of formal medical practice and its practitioners. Using diaries, letters, accounts, and commonplace books from many of the major family and estate collections of the county, the article will trace the outlines of alternative medical provision, concentrating particularly on the issue of self-medication, and provide an initial perspective on the role of irregular healers. ${ }^{15}$ Our basic aim has been to draw out the essential complexity of regional and local medical systems, and to highlight the value of more work of the sort which we have undertaken. Within this framework, there are things which the article consciously does not set out to do. We have ignored some important elements of medical practice, such as midwifery, which have been well documented elsewhere. ${ }^{16}$ For reasons which will become apparent below, we have also ignored evidence from medical directories. The article does not provide an exhaustive survey of the way in which the actuality and perception of the medical landscape changed during the lives of individuals and families. Nor does it provide a truly comprehensive overview of the middling medical scene at any single point in time. Given the way in which records for the county are split up between private collections, uncatalogued record office collections, local libraries and the county record office, and given the interpretative problems to which we have already referred, a much wider project would be needed to achieve this end. ${ }^{17}$ Finally, we do not claim to provide a comprehensive overview of the lives of Lancashire doctors. This will be the focus of later work.

\footnotetext{
${ }^{14}$ The definition of "middling" is of course problematic. While reference is occasionally made here to minor aristocracy, much of the article focuses on those without titles and substantial landed estates. The families concerned held land in some form, served public office in their locality and were sufficiently affluent to be able to afford the services of a physician on a regular basis. No distinction is made in this loose definition between old and new wealth. Liverpool and Manchester are largely ignored in this analysis because of the danger of focusing on two places which, even at the peak of their expansion, accounted for less than two-fifths of the Lancashire population. We hope to follow up medical care in the cities in subsequent work.

${ }^{15}$ All of the sources used here are subject to problems of inclusivity, representativeness and
}

interpretation. Some of these issues are addressed in S A King, 'Power, representation and the self: problems with sources for record linkage', Local Historian, 1997, 24: 1-11.

${ }^{16}$ See the excellent article by D Harley, 'Provincial midwives in England: Lancashire and Cheshire 1660-1760', in H Marland (ed.), The art of midwifery: early modern midwives in Europe, London, Routledge, 1993, pp. 27-48.

${ }^{17}$ Of course, this means that some of the lines of enquiry pursued here are based upon small numbers of cases. In future, more detailed, work we hope to show that the local and regional differences which we identify in this article are based upon secure interpretation of the sources, and have much wider resonance in the counties of the northwest. 


\section{Lancashire: The Regional Framework}

Lancashire provides an ideal test bed for exploring the value of detailed regional analysis in a number of ways. ${ }^{18}$ In the first place, its population was historically (and remains today) "unhealthy" compared with those of other counties and regions. By the later eighteenth century, industrialization, urbanization, proto-industrial development and rapid population growth had given Lancashire cities and towns a record of infant, childhood and adult mortality, which was among the worst in the country. ${ }^{19}$ Even town hinterlands and rural communities in the county experienced mortality levels well above comparable areas in other industrializing regions. ${ }^{20}$ The reverse side of the high mortality coin is often poor health, and evidence from diaries, letters, and other family papers reveals endemic poor health. ${ }^{21}$ Ralph Standish, from Standish, near Chorley (Figure 1), experienced nineteen different bouts of ill health lasting more than three days in the course of six years in the early eighteenth century. ${ }^{22}$ Thomas Tyldesley from Garstang near Preston spent almost as much time confined to his chamber with different ailments between October 1712 and May 1713 as he did conducting "normal" life with his family and friends. ${ }^{23}$ Between 1771 and 1788, the correspondence of the Langton family of Kirkham near Preston was heavily concerned with family health problems, providing detailed reviews of illness and accounts of trips to take spa waters. ${ }^{24}$ The Albinson family from near Bolton was seemingly never free from ill health and the threat of death to various family members between 1795 and the 1820 s. $^{25}$ Long connection with the medical profession was little help in ensuring good health. The Whitacker family of Clitheroe had a series of medical men in its lineage and could trace its medical roots back to a licence in 1669 , but voluminous correspondence from the late eighteenth and early nineteenth centuries reveals a catalogue of fevers, diseases of childhood, accidents and minor ailments. ${ }^{26}$

\footnotetext{
${ }^{18}$ Lancashire was not a self-contained regional unit. However, the Mersey to the south, the Irish Sea to the west and the Pennines and Trough of Bowland to the east formed important natural barriers. The socio-economic and cultural differences between West Yorkshire and east Lancashire on the one hand, and between south Lancashire and north Cheshire on the other, were very strong indeed. Only in north Lancashire, where the county bordered Westmorland and North Yorkshire, is it possible to speak of a continuum of experience which crossed administrative boundaries. This issue is considered in S A King, 'Rethinking the English regions: sixteenth to nineteenth centuries', in S Brakensieck and A Flugel, op. cit., note 8 above, pp. 89-121.

${ }^{19}$ For a general view, see the various contributions to Transactions of the Historic Society of Lancashire and Cheshire, 1993: 143.

${ }^{20}$ See, for instance, P Huck, 'Infant mortality in nine industrial parishes in northern England 1813-1816', Popul. Stud., 1994, 48: 513-26. In the small north-east Lancashire town of Colne, the
}

infant mortality rate at 201 per thousand between 1750-1820 was well above national levels. See S A King, 'A question of urban geography: life and death in Colne 1650-1820', (unpublished paper available at Oxford Brookes University library).

${ }^{21}$ For a general survey, see R Porter and D Porter, In sickness and in health: the British experience 1650-1850, London, Fourth Estate, 1988.

${ }^{22}$ Wigan Record Office (hereafter WRO): D/D/St.E/1, 'Memorandum and account book of Ralph Standish, 1721-1727'.

${ }^{23} \mathrm{~J}$ Gillow and A Hewitson (eds), The Tyldesley diary: personal records of Thomas Tyldesley, Preston, Gillows, 1873.

${ }^{24} \mathrm{~J}$ Wilkinson (ed.), The letters of Thomas Langton, flax merchant of Kirkham 1771-1788, Manchester, Chetham Society, 1994.

${ }^{25}$ Bolton Local Studies Library (hereafter BRO): ZZ/223, 'Albinson collection'. Particularly item 2, a commonplace book 1795-1835.

${ }^{26}$ Lancashire Record Office (hereafter LRO): DDWh $/ 4$, 'Correspondence'. 


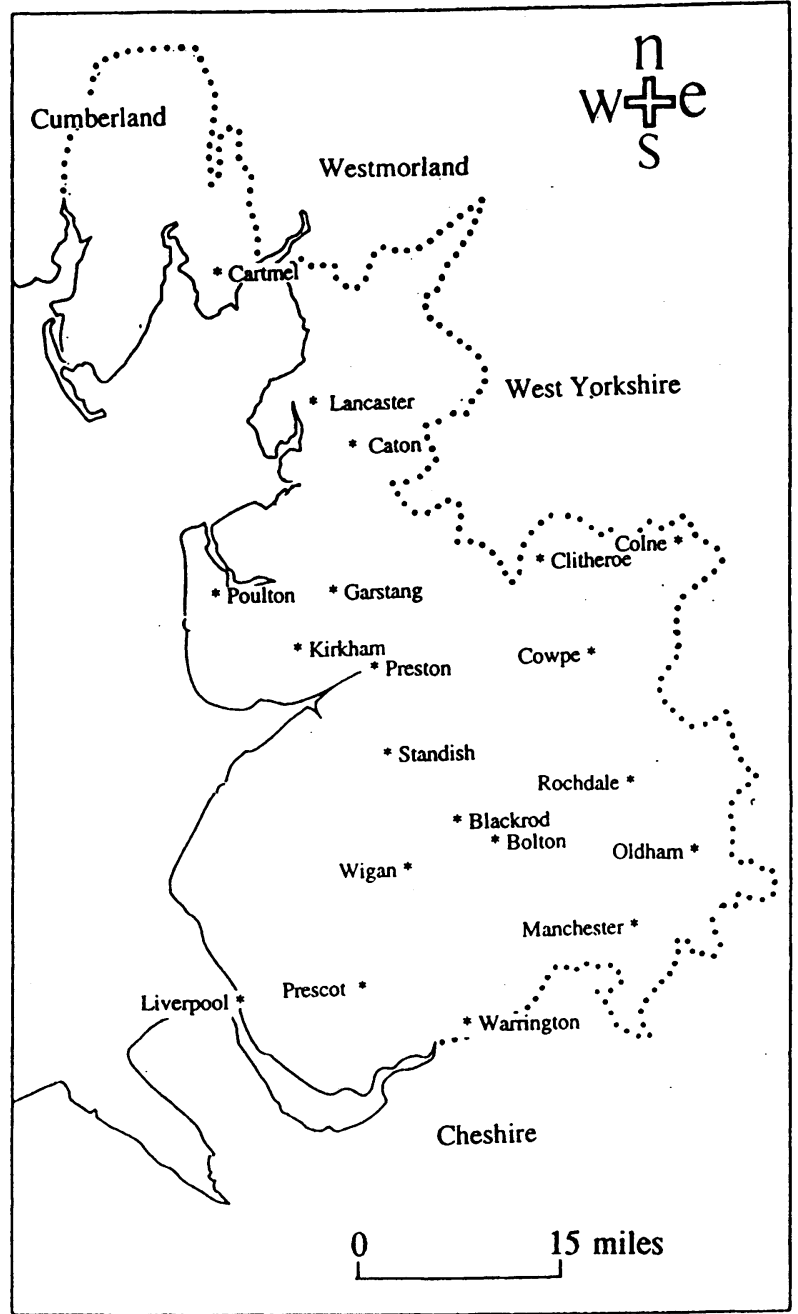

Figure 1: Location map of Lancashire (pre-1974 boundaries).

Notional demand for medical services because of the scale of ill-health should thus have been considerable. Wider changes in the number of potential consumers and the relative wealth of the county should have reinforced such notional demand. Proportionate population growth in Lancashire after 1750 was faster than in any other English county. Even if we exclude the contribution of Liverpool and Manchester, Lancashire could boast the third fastest county population growth from 1790. Such growth notwithstanding, the county sprang from being one of the poorest areas of England in 1700 , to one of the richest by the 1820 s. Alongside London and some of the other provincial centres, Lancashire developed a burgeoning group of urban and rural middling families who might have been expected to demand an ever 
increasing range of medical services, and the county also retained a central core of affluent landowners during the eighteenth and nineteenth centuries. ${ }^{27}$ If, as much of the literature would have us believe, the consumer revolution of the eighteenth and nineteenth centuries stimulated an upsurge in effective demand for all forms of medicine as a consumption item, then we might expect to see a vibrant medical culture developing in the county.

The second reason why reconstruction of the medical landscape in Lancashire is instructive, however, is that the nature of familial responses to these stimuli is obscure. Despite high notional demand for medical services, both Digby and EvendenNagy characterize the county as poorly provisioned with medical men between the seventeenth and nineteenth centuries. ${ }^{28}$ Lancashire was consistently near the bottom of the league table of practitioner-to-patient ratios, and even if we accept Loudon's conclusion that by the opening decade of the nineteenth-century there were nine irregulars for every regular practitioner, Lancashire would still appear to have been weakly doctored. ${ }^{29}$ Explanations for this experience are not at once clear, but what is certain is that the availability of medical services outside formal doctoring must have been complex. It is unfortunate that we know so little about it. The early work of Bosdin-Leech on structures of medical care has not led to a systematic regional study. ${ }^{30}$ We know something about institutional provision for the sick, and about the care of the sick poor. ${ }^{31}$ However, we know next to nothing about middling medical consumers, and discussion of self-dosing, quackery, superstition, and informal practitioners has been very muted. What is needed is not just a study of formal medical practice in Lancashire (though this is much overdue) but also a broad survey of the range of other avenues for medical treatment open to middling Lancashire families.

Yet this will not be easy. The third reason why Lancashire acts as a useful testbed for regional studies is that the county had so many levels of sub-regional identities. The substantially Catholic southwest of the county can be contrasted to the mainly Anglican north and east. By 1800 there was a sharp dividing line between

\footnotetext{
${ }^{27}$ See A Vickery, 'Women of the local elite in Lancashire $1750-1825$ ', $\mathrm{PhD}$ thesis, University of London, 1991, and A Vickery, 'Women and the world of goods: a Lancashire consumer and her possessions, 1751-81', in $\mathrm{J}$ Brewer and R Porter (eds), Consumption and the world of goods, London, Routledge, 1993, pp. 274-302.

${ }^{28}$ Digby, op. cit., note 6 above, and $\mathrm{D}$ Evenden-Nagy, Popular medicine in seventeenth century England, Ohio University Press, 1988. We are grateful to one of the referees for the observation that imperfect information and transport infrastructures, as well as the unfashionableness of Lancashire, may have contributed to this paradox.

${ }^{29}$ I Loudon, Medical care and the general practitioner 1750-1850, Oxford University Press, 1987. I Loudon, “"The vile race of quacks with which this country is infested"', in Bynum and
}

Porter (eds), op. cit., note 1 above, pp. 106-28, and R Porter, 'The patient in England $1660-1800$ ', in Wear, op. cit., note 9 above, pp. 91-118.

${ }^{30} \mathrm{E}$ Bosdin-Leech, Early medicine and quackery in Lancashire, Liverpool, Ranold Press, 1938. Pickstone's general survey had a broad south-east Lancashire focus. See J V Pickstone (ed.), Health, disease and medicine in Lancashire 1750-1950: four papers on sources, problems and methods, Occasional Paper 2, Manchester, Department of History of Science \& Technology, UMIST, 1980.

${ }^{31} \mathrm{~J} V$ Pickstone, Medicine and industrial society: a history of hospital development in Manchester and its region 1752-1946, Manchester University Press, 1985, and A Fessler, 'The official attitude towards the sick poor in seventeenth century Lancashire', Transactions of the Historic Society of Lancashire and Cheshire, 1950, 102: 79-122. 
the highly urbanized communities of southeast and central Lancashire, and the very rural communities north of Preston. There was an equally sharp dividing line between the textile industries of east Lancashire, and the heavy and extractive industries of central and southwest Lancashire. Liverpool and Manchester stood at either corner of the south of the county, but had remarkably limited hinterlands, with satellite towns such as Wigan, Bolton, and Bury rapidly diluting the circle of influence of the two great conurbations. Population densities showed no systematic pattern outside the contrast between the rural north and the cities, but literacy varied widely, from the extremely poor standards of the Fylde to the very high standards of Rossendale. On top of all of these levels of spatial identity, it is important to note that individual communities and localities claimed and defended distinctive accents, cultural identities, and structures of mythology and superstition, some of which endure today. The development of the medical landscape in Lancashire was thus part and parcel of, and partly superimposed upon, a complex set of sub-regional boundaries with blurred edges.

For the period after 1750 , Figure 2 attempts to map out the sub-regional structure of Lancashire. The boundaries are constructed by mapping religion, basic topography, the distribution of industry-types, population density, wealth distributions, and the density of transport networks. A comprehensive reading of contemporary local histories has also revealed sub-regional differences in the structure of mythology, and this indicator was used to finalize the boundaries between sub-regions. For this reason, the boundaries appear as distinct whereas in practice they probably overlapped. ${ }^{32}$ As in any exercise of this kind, the scope for interpretation of what makes a "sub-region" and where it should be located is considerable. However, the point is not whether the boundaries which appear in Figure 2 are exactly right but rather that there are grounds for trying to draw them in the first place. On this issue we are on safer ground. Even early antiquarian historians realized the existence of sub-regional boundaries in Lancashire, and most modern Lancashire historians would recognize labels such as central, northeast and southwest Lancashire. We are not, therefore, simply trying to shape medical history arbitrarily to fit defined spatial boxes. Rather, in what follows we will integrate the issues of sub-regional identity and medical history to suggest that medical consumerism did not wash over all these subregions equally during the eighteenth century, and that simple conceptions of a division between urban and rural Lancashire in terms of the medical landscape have to give way to more important spatial divisions between broadly defined "east" and "west" Lancashire. Our starting point is the medical professional. ${ }^{33}$

\footnotetext{
${ }^{32}$ This map is drawn from King, op. cit., note 18 above, from where further details of the logic and sources for these sub-regional boundaries can be obtained.

${ }^{33}$ There are of course different degrees of medical professional. We are less concerned with
}

nominal distinctions than with the question of whether a "doctor" treated middling patients or not, and so the term "doctor" encompasses all grades of medical professional for the purposes of this analysis. 


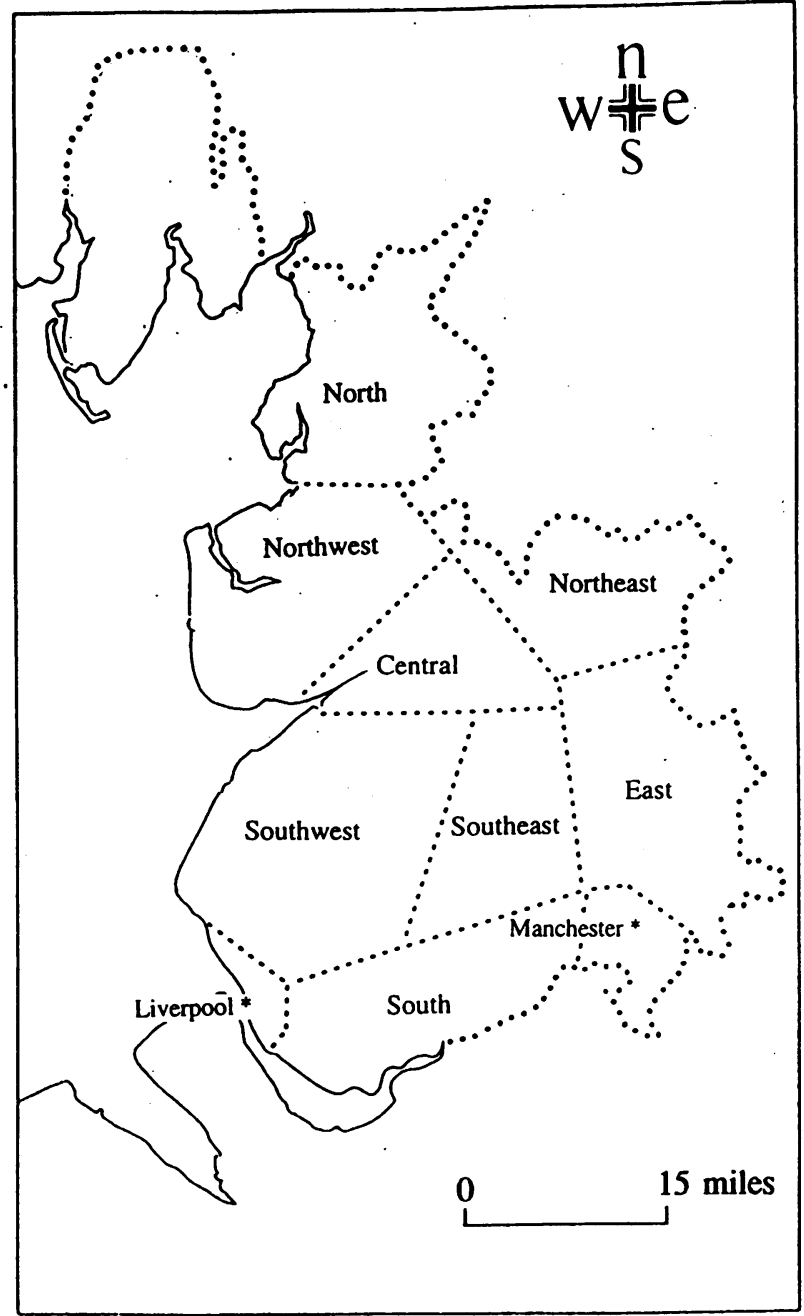

Figure 2: Sub-regional boundaries in Lancashire.

\section{Varieties of Doctor-Patient Relationships}

To say simply that the county was "under-doctored" is a poor characterization of the complexity of the role of the doctor in Lancashire society, and of the wider medical scene. Within a general framework of high doctor-patient ratios, the cities and their immediate hinterlands were well provided with medical personnel. Depending upon whom we include under the label "doctor" and how we draw the boundaries of Liverpool and Manchester, doctor-patient ratios in the two cities were under 1:500 by the 1770 s and 1780s. Rapid urban growth thereafter outstripped the supply of medical men, but ratios were generally under 1:2000 patients before the 1830s. This article will not consider these city-based medical men or urban medical 


\section{Steven King and Alan Weaver}

provision in general. There are good reasons for this strategy. We have already noted the danger of concentrating on a relatively small proportion of the Lancashire population by dwelling on experiences in the two cities. Even if we wanted to, the survival of detailed personal papers for city doctors is patchy. At the end of the period considered here, the papers of Dr Edmund Lyons, physician to the Manchester Infirmary between 1817-1841, provide an overview of the medical practice of a city doctor. ${ }^{34}$ The important pamphlet writing of some Lancashire city doctors also survives, and we have thumbnail sketches of most important urban doctors and their work. ${ }^{35}$ However, the vast majority of city doctors recorded in medical directories have left sparse records of their own, and the family collections of their patients are also remarkably limited. ${ }^{36}$ In any case, one could suggest that city-based medicine became increasingly isolated from that in the rest of the county in the eighteenth century. During the early 1700s the Blundell family from Crosby near Liverpool made considerable use of city doctors, but outside a ten mile radius around Liverpool or Manchester it appears to have been relatively uncommon for middling or elite families to make similar use of medical men from the city. The vicar of Prescot called on doctors from Wigan, while coal mine owners in St Helens used doctors from Warrington in preference to those from Liverpool. On the other side of the county, it was rare for prominent families like the Heywoods from Bolton to call on the services of Manchester doctors. ${ }^{37}$ There may even have been differences of practice. Richard Kay, for instance, periodically travelled between Bury and Manchester for what were in effect refresher courses.

The need for a systematic study of the doctoring trade in Lancashire, as in other individual English regions, is pressing. In the meantime, if we were to exclude from the calculation of doctor-patient ratios Liverpool, Manchester, and their immediate hinterlands, large parts of Lancashire would appear as much more "under doctored" than even Digby or Evenden-Nagy have allowed. By the opening decade of the nineteenth century, for instance, the towns and hinterlands of Wigan, Burnley, Chorley, Garstang, and Rochdale had doctor-patient ratios approaching an average $1: 3000 .^{38}$ However, these bland figures tell us little about the character and role of

\footnotetext{
${ }^{34}$ Manchester Central Library (hereafter MCR): N/134, 'The papers of Dr Edmund Lyons, 1790-1862'.

${ }^{35}$ See J G Adami, Charles White of Manchester (1728-1813) and the arrest of puerperal fever, London, Hodder, 1922.

${ }^{36}$ Though see W J Elwood and A F Tuxford (eds), Some Manchester doctors: a biographical collection to mark the 150th anniversary of the Manchester Medical Society 1834-1984, Manchester University Press, 1984, also, E M Brockbank, Sketches of the lives and works of the honorary medical staff of the Manchester infirmary from its inception in 1752 to 1830 when it became the Royal Infirmary, Manchester University Press, 1904, and W Brockbank, The honorary medical staff of the Manchester Royal Infirmary 1830-1948, Manchester University Press, 1965.
}

${ }^{37}$ See also BRO: ZZ/357, 'Physick in Bolton in 1779'. David Harley has produced an illuminating survey of licensed northwest physicians prior to 1760 based upon probate and ecclesiastical materials, but he does not adopt a specifically Lancashire focus. See D Harley, "Bred up in the study of that faculty": licensed physicians in north-west England 1660-1760', Med. Hist., 1994, 38: 398-420.

${ }^{38}$ For population figures, see C B Phillips and $\mathrm{J} \mathrm{H}$ Smith, Lancashire and Cheshire from $1540 \mathrm{AD}$, London, Longman, 1993. Figures for the number of practitioners are drawn from one of three sources: medical directories, surveys of local medical expertise by Poor Law authorities, and local newspaper commentary. It is important to note that the residence of doctors can provide only a nominal indicator of where they actually made their living. 


\section{The Medical Landscape in Lancashire, 1700-1820}

doctoring outside the cities, and indeed mask important and intriguing sub-regional differences in the activity of doctors and their relationships to patients. The most important division was between the areas in Figure 2 defined as northwest, central and southwest Lancashire (a broadly defined "west"), and those defined as north, northeast, east and southeast Lancashire (a broadly defined "east").

We can begin to exemplify some of these complexities using the account book of Dr Richard Loxham (1725-1791), from Poulton in the Fylde area of northwest Lancashire, which contains 300 patient treatment and payment histories stretching over the middle decades of the eighteenth-century. ${ }^{39}$ This source does not provide the detailed commentary on patients and their health which can be found in casebooks of the sort kept by the Cumberland doctor William Brownrigg, John Snow, or John Hall. ${ }^{40}$ However, in conjunction with other records, it yields a way into the question of the character of doctoring and the nature of doctor-patient relationships in "west" Lancashire. Thus, like doctors in other counties, Richard Loxham showed a willingness to travel long distances for selected patients, and to correspond by post on illnesses and their cures. He journeyed as far as Manchester and Warrington in the south of the county, Rochdale in the east and Caton in the north, as well as travelling extensively in the Fylde itself. However, 95 per cent of his patients were to be found within a radius of 10 miles round Poulton. The range of treatments which Loxham employed would not look out of place in any of the treatment books available for different parts of the country, and nor, perhaps, would the sliding cost scale which he applied to patients according to his determination of their ability to pay. Like that of doctors elsewhere, Loxham's patient body consisted of a small core of families who had a long-term relationship with him, and a much larger number of those who were treated only once or at best intermittently. He was perhaps more unusual in the relative balance of these two types of patients. His core families numbered just 23, and while many prominent middling families appeared in his account book most did so only once, usually for very serious illnesses. He was also unusual in his financial dealings. Caught up in the Lancashire credit economy, his account book is littered with postponed debts and payments in kind, and he made consistent efforts to diversify his sources of income. Loxham had a stake in the local public house which he used as his treatment room for patients, and he also took rents from cottages and land. ${ }^{41}$

\footnotetext{
${ }^{39}$ LRO: DDPr/25/6, 'The account book of Richard Loxham'. Loxham was a relatively prosperous medical man who styled himself a surgeon.

${ }^{40} \mathrm{~J}$ E Ward and J Yell (eds), The medical casebook of William Brownrigg MD (1712-1800) of the town of Whitehaven in Cumberland, Medical History, Supplement 13, London, Wellcome Institute for the History of Medicine, 1993. Also, R H Ellis (ed.), The case book of Dr John Snow, Medical History, Supplement 14, London, Wellcome Institute for the History of Medicine, 1994, and J Lane, John Hall and his patients: the medical practice of Shakespeare's son-in-law, Stratford, Shakespeare Birthplace Trust, 1997.
} 


\section{Steven King and Alan Weaver}

Clearly, Loxham is worthy of more detailed study, but the key point for this analysis centres on the relationship which he had with his patients. Much of the evidence reviewed so far suggests that such relationships were shallow, and linking patient records with material from the rich estate collections for the Fylde confirms that Loxham did not enter into the easy familiarity with his patients which was common elsewhere..$^{42}$ Despite the fact that he treated prominent Lancashire families such as the Cliftons, Claytons, and Ashworths, there appears to be no correspondence which refers to him in surviving family papers. His bills may have been recorded, but his relationship with patients was often short term and always very functional. Though he had a relatively dense patient body within a limited radius of Poulton, Loxham could be characterized as having a tenuous hold on the medical lives of his patients, and he certainly felt the need to reduce his dependence on medical income over the course of his professional career.

Of course, Loxham is a single example, and one could argue that the vagaries of source survival and the fact that he was trawling the bottom end of the middling medical market influence what we read into the case. Yet, other doctors in this northwest sub-region seem to have had similar experiences. John Nixon of Roseacre appears in none of the correspondence of the principal Fylde landed and middling families, even though he certainly served them, and notwithstanding his efforts to take on a landed estate to gain status and respectability above that provided by his profession. ${ }^{43}$ Dr Francis Carter of Poulton had to assign his goods to creditors in 1787 for a debt of just $£ 40$, despite the fact that he had connections with the Clifton family. ${ }^{44}$ James Wright of Lancaster treated 220 people in the fifteen years between 1785 and 1800 , but never saw the same patient or other patients from the same family more than twice. ${ }^{45}$ Nor did other medical men in the sub-regions of "west" Lancashire fare much better with their patients. Two of the most prominent Prestonbased doctors - William St Claire and Edward Pearce-must have made a substantial part of their living from, and certainly had closer links with, families to the east, rather than those from Preston, its hinterland or families to the north and south of the town. As we will see below, St Claire had particularly strong relationships with members of the Whitacker family of Clitheroe, but manifestly failed to manufacture the same kind of ties with families of equal social status within a ten mile radius of Preston. There was certainly nothing in the nature of local transport networks or wealth levels which would have made this outcome inevitable. Meanwhile in the southwest sub-region, James Law treated most of the major middling families between Preston and Wigan, but was obliged to liquidate property and land over a ten-year period between 1800 and 1810 to maintain the trappings of a doctor in the face of his inability to build ongoing connections with them. ${ }^{46}$

Medical directories would reveal a body of practitioners not considered in this

\footnotetext{
${ }^{42}$ Lane, op. cit., note 11 above, and Barry, op. cit., note 5 above.

${ }^{43}$ See LRO: DDPr/16/11, 'Property indenture, 1800 ' in which John Nixon of Roseacre has outbid two chapmen to gain the lease on an estate in the Fylde.
}

${ }^{44}$ LRO: DDPr/17/11-12, 'Debts and inventory of Dr Francis Carter, 1787'.

${ }^{45}$ Lancaster Local Studies Library, 'Wright papers'.

${ }^{46}$ WRO, 'Law collection'. 
analysis, and there are inevitable questions of representativeness. Ultimately, there is no way of knowing how far Loxham, St Claire, Law, Nixon and others were representative of those medical men who have left no records. However, one reading of this evidence would be that notional and effective demand were two very different animals in "west" Lancashire. Middling families did use doctors, but not intensively. Even where there was a consistent medical relationship, it was usually not accompanied by the close personal ties which literature on other areas encourages us to expect. These conclusions are confirmed if we look at the medical landscape from the point of view of middling patients in the western sub-regions for whom records survive. Many demonstrated considerable suspicion of formal doctoring and doctors, and some actively rejected formal medical intervention altogether. ${ }^{47}$ The Lancaster merchant, William Stout, talked of his father as "never inclind to make use of doctors or phisick" ${ }^{48}$ Stout himself called in a doctor when he was beset with rheumatism in 1688, but then spent the rest of his autobiography stressing how he and his family rejected recourse to doctors, even when advised to the contrary. Thus, in 1717, Stout got a violent fever and stomach pains but refused a doctor, while his sister vomited blood and "was advised to apply to a doctor but was always averse to it". ${ }^{49}$ Only when in his seventies and suffering a broken leg and internal bleeding because of a horse accident did Stout call in the doctor. Even then, he steadfastly refused "Phisick". 50

William Stout was rich and had a range of medical practitioners available to him in early eighteenth-century Lancaster. His perspectives on medicine were not constrained by simple economics, but the fact that he was a Quaker may have influenced his attitude rather more fundamentally. However, a similar scepticism of formal medicine can be gleaned from a reading of the papers of other middling families for whom religion was probably a less prominent influence on interpretation of health and illness, and on attitudes towards the use of medicine. A number of brief case studies from a wider sample which we could have deployed, illustrates this central point. Thomas Tyldesley bought and applied his own leeches, and his wife undertook blood-letting. They do not appear to have consulted a doctor even for illnesses which stretched over several months at a time. ${ }^{51}$ The Machell family of Haverthwaite on the Cartmel peninsula in northwest Lancashire called upon the services of Dr John Fell between April 1781 and February 1782. In that time, they were charged for orange peel, cathartic draughts, powders, emulsions, purgative, oil of sweet almonds, salts, and pills for a young lady aged 21 who died while visiting

\footnotetext{
${ }^{47}$ A suspicion of the limited kit bag of doctors was of course more widely felt. See Loudon, op. cit., note 9 above, p. 229, and Porter, op. cit., note 29 above, pp. 98-100. Pickstone took Lancashire's medical botany movement as evidence of opposition to formal medical practitioners right down the social scale. See Pickstone, op. cit., note 30 above, and J Percy, 'Scientists in a humble life: the artisan naturalists of south Lancashire', Manchester Region History Review, 1991, 5: 3-10.
}

\footnotetext{
${ }^{48} \mathrm{~J}$ D Marshall, The autobiography of William Stout of Lancaster 1665-1752, Manchester University Press, 1967, p. 74.

${ }^{49}$ Ibid., p.178. Stout chose to confront his own ailments with "patience and resignation", p. 171.

${ }^{50}$ Ibid., p. 221.

${ }^{51}$ Gillow and Hewitson, op. cit., note 23 above.
} 
the household. After her death, the services of Dr Fell were dispensed with and the family appears never again to have referred to a formal medical professional. ${ }^{52}$ The Langton family of Kirkham in northwest Lancashire can also be found rejecting formal medical help in the later eighteenth century. As Joan Wilkinson notes, no doctor was ever called to treat the chronic long-term weakness of Mrs Langton, or to deal with failing sight and eventual blindness in one of the Langton sons. In June 1776, Thomas Langton on a journey back to Lancashire received a note to say that the family had called in the doctor because of smallpox in one of the sons. He approved of the action "on this occasion" but not otherwise. ${ }^{53}$ Meanwhile, the records of the Clayton family of Lostock Hall in central Lancashire provide a detailed late eighteenth- and early nineteenthcentury record of the landscape of illness and cure open to Lancashire families. They too showed a scepticism of doctoring. In November 1802, Dr Law called at the Claytons' house. Dolly Clayton was unable to come down because of chronic rheumatism, but the doctor's offer of help was rejected in favour of traditional herbal remedies. ${ }^{54}$ Even among the well-educated there is evidence of a developed suspicion of formal medicine. Thus, in 1803, the Wigan clergyman the Reverend Dr Bateman wrote to his friend the Reverend Dr Reynolds of Oxford University, advising him to reject the advice of doctors and to use a recipe based upon chives as a means of stopping bleeding, healing wounds and fighting infections, and setting out a number of extraordinary situations in which his recipe had been successful where other formal treatments had not. ${ }^{55}$

It is implicit in these examples that the chronology of increased uptake of the services of doctors by middling families which applies elsewhere had only limited relevance to the sub-regions of "west" Lancashire. Here we can see not only a long familiar tradition of the formal medical practitioner being the last port of call, but also of a much more active and deep-rooted distrust of such people on the part of many middling families. For doctors, this meant limited patient books, economic instability, and often a failure to play a prominent part in wider local and regional life.

We can contrast this situation with that in east, northeast, and southeast Lancashire. Here, doctor-patient ratios were similar to those in the "west" but middling and landed families appear to have used doctors more intensively and involved them more closely in their family affairs. Some of this can be clearly seen in the diary of Richard Kay, of Baldingstone near Bury in east Lancashire. He took over a family business and had enduring professional and private relationships with many of his

\footnotetext{
${ }^{52}$ See LRO: DDMc/28/3/5, 'Medical accounts'.

${ }^{53}$ Wilkinson, op. cit., note 24 above.

${ }^{54}$ LRO: DDx/510, 'The diaries of Dolly

Clayton of Lostock Hall, 1777-1837'. Doctors were used of course, but often only for sudden and uncontrollable problems.
}

\footnotetext{
${ }^{55}$ LRO: DDGa/17/1066, 'Letter from the Revd Dr Bateman to the Revd Dr Reynolds describing some extraordinary cures by the use of chives and goose grass'.
} 
patients, of the sort which might have attracted the envy of Richard Loxham. ${ }^{56}$ The fragmentary accounts of Dr James Whitehead (1749-1829) of Cowpe in east Lancashire, who practised between 1790 and 1826, reinforce the conclusions which can be drawn from the experience of Richard Kay. Like Kay, he took over from his father and maintained healthy personal and professional relations with many of the 90 per cent of his patients who were to be found within a radius of fifteen miles around Cowpe. While Richard Loxham could manage a long-term doctoring relationship with only 8 per cent of his patients, Whitehead saw 34 per cent of his patients regularly over three years or more. Moreover, while in "west" Lancashire James Law was disposing of assets and Richard Loxham was reducing his reliance on medical income, in "east" Lancashire Whitehead was actively divesting himself of other income-generating roles to concentrate on doctoring. ${ }^{57}$

The same broad conclusions about the character and role of doctoring can be applied to other sub-regions in this area. In the "northeast" township of Colne during the 1790s, John Turner was styled a surgeon in the parish registers and appears to have acted as a doctor to middling families in the town. As with the other medical men reviewed so far, he took over the Colne business from his father and thrived in an economic sense. Unlike Drs Loxham, Carter, Nixon and Law in northwest Lancashire, John Turner appears to have had a strong public persona and to have built up enduring personal and professional relations with his clients. He witnessed the marriages of some of the children of his middling patients, witnessed and executed wills, and was a prominent member of the local vestry. Also in "northeast" Lancashire, the relationship between the Whitacker family from near Clitheroe and their doctor, William St Claire (1783-1839) of Preston, was very close indeed. St Claire acted as godparent to one of the Whitacker children, Mrs Whitacker regularly wrote seeking advice and attendance from St Claire on even the smallest medical matters, while St Claire and Mr Whitacker regularly exchanged gifts of fish and game. The doctor had a network of relationships in northeast Lancashire, apparently found it easy to procure nurses at short notice from the local area, and corresponded and acted with most of the other local doctors around Clitheroe. ${ }^{58} \mathrm{In}$

\footnotetext{
${ }^{56} \mathrm{~W}$ Brockbank and F Kenworthy (eds), The diary of Richard Kay (1716-51): of Baldingstone, near Bury, a Lancashire doctor, Manchester University Press, 1968. We are grateful to one of the referees for pointing out that long residence in his locality, relatives in the local and regional trade, and religious links with local patients, may all help to explain these closer connections in addition to the conscious relationships between doctor and patients.

${ }^{57}$ Rawtenstall library, 'Waterfoot mill collection'.

${ }^{58}$ LRO: DDWh/4/12,87 and 91-116, 'Medical correspondence'. St Claire arranged lodgings for the Whitackers when they were in west Lancashire and also acted as their rent collector. $\mathrm{He}$ was one of the initial appointments to advise
}

at the Preston dispensary. Interestingly, St Claire does not ever seem confident of his own authority in his relationship with the Whitackers, always sending his own prescriptions but also suggesting an equally effectual herbal remedy. The patient narrative survives rather longer in this relationship than it appears to do elsewhere. St Claire had an equally close relationship with the Parker family of Brownsholme, who appear to have lent him money to cover laggardly payment. LRO: DDb, 'Parker of Brownsholme'. Instances such as these might be multiplied manyfold. Charles Walmsley of Clitheroe helped the son of his doctor, Thomas Jackson, to find a position as a lawyer after he came out of articles in London, lending him over $£ 800$ to set up in practice. LRO: DDWa, 'Unlisted correspondence'. 
the southeast sub-region, the Heywood family from near Bolton, cotton manufacturers and radicals, had similar relationships with their two physicians, Dr Turner and Dr Law. Turner acted as surety for a mill extension, and the diaries of the Heywood family suggest that both doctors were regular personal, as well as professional, visitors to the family home..$^{59}$

The correspondence of middling families from these sub-regions can be used to bolster this analysis by giving a "patient view" of the medical landscape. The archives of the Whitacker, Heywood, Towneley, Parker, and Richardson families, for instance, provide rich testimony to a medical culture which carved out a central niche for medical professionals. However, these stories simply confirm the key point that in a broadly conceived "east" Lancashire we see the sorts of social, economic and professional relationships between doctor and patient familiar from studies of other parts of England. They reflect a much wider "doctor-centred", "doctor sensitive" and dynamic middling medical culture in this area. Thus, when Dr Hawarden of Blackrod in southeast Lancashire, surgeon and apothecary, was killed in a shipwreck off the coast of Ireland in the later eighteenth-century, the local newspaper published a long poem in his honour composed by "Blackrodienisis". ${ }^{60}$ In Oldham, Dr William Brennand was challenged to a duel in February 1788 by John Clegg, a cotton manufacturer of Manchester. The diarist William Rowbottom recorded this event, noting with admiration the courage of the doctor and the sense of the doctor's friends in averting the duel. Indeed, newspaper reporting suggests that representatives of some of the most important families in the area had turned out to support "their" doctor. ${ }^{61}$ Medical men were not always so favourably treated. Playbills for the Bolton area during the eighteenth and early nineteenth centuries suggest that they could also be the subject of parody in local plays. ${ }^{62}$ Whether they were used intensively or parodied mercilessly, such evidence suggests that doctors had a higher profile in this broadly conceived "east" than was the case in the "west", and alongside this a much more secure income and status from the doctoring trade. ${ }^{63}$ In this context, it is notable that no correspondence for doctors officially resident in the east, northeast,

\footnotetext{
${ }^{59}$ BRO: ZHE, 'Heywood family papers'. For similarly close relationships between other southeast Lancashire families and their doctors, see WRO: EHC 24A/RM1588, 'Wrottesly papers'.

${ }^{60}$ BRO: ZZ 423/7, 'Poem on the death of $\mathrm{Mr}$ Hawarden'.

${ }^{61}$ A Peat, 'The most dismal times': William Rowbottom's diary 1787-1799, Oldham Borough Council, 1996, pp. 19-20.

${ }^{62}$ BRO: ZZ/82, 'Bolton playbills'. The mideighteenth-century work of the writer and poet Tim Bobbin (alias John Collier), some of which parodied both regular and irregular practitioners in a similar way, was also based upon his experiences in east Lancashire. See $\mathbf{J}$ and $\mathrm{P}$ Bond, Tim Bobbin lives! The life and times of a Lancashire legend, Milnrow, Gilbert, 1986, also, M Geshwind, 'Tim Bobbins's
}

\begin{abstract}
Lancashire hob and the quack doctor', Bull. Hist. Dentistry, 1995, 43: 119-23. For a wider perspective, see F Butler (ed.), The doctor on the stage: medicine and medical men in seventeenth-century England (as portrayed in plays), Knoxville, Tennessee University Press, 1967.

${ }^{63}$ The broad character of these sub-regional differences would appear to be true of people at all social levels. It was relatively common for ratepayers and others in the "east" of the county to raise a subscription to send poorer people to doctors whose rates could not be paid from Poor Law funds, whereas these displays of communality were not evident in the 'west'. See BRO: ZZ/3/16, 'Subscription list', and S A King, Poverty and welfare in England 1700-1850, Manchester University Press, 1999.
\end{abstract}


and southeast was to be found in the family collections of western and central Lancashire. Nominal and effective demand were close in the "east". As the example of William St Claire shows, the same is not true in the "west".

These apparent sub-regional differences in effective demand within a general framework of high doctor-patient ratios outside the main Lancashire cities and their hinterlands, are not at once easy to explain. David Harley has suggested that there might be a link between Catholicism and the strength of recourse to alternative forms of medical care ${ }^{64}$ There were more Catholics in "west" Lancashire than in the "east", and it is certainly true that some prominent Catholic families were very sparing in their use of formal medical provision. There is also evidence that such families had a wider influence on attitudes towards doctors, partly maintaining their traditional patronage and status through the provision of medical care to the locality using their own recipe books, time and money. By the early nineteenth century, for instance, Thomas Eccleston of Scarisbrick in southwest Lancashire was keeping a commonplace book specifically constructed to distribute to local farmers and landowners with a view to treating complaints ranging from dropsy to colds and fevers. ${ }^{65}$ However, the picture is clearly more complicated than this. Anglican, Catholic and Nonconformist families alike showed less tendency to use medical men in the three western sub-regions than their counterparts in the east, northeast, and southeast of the county. Yet, other "obvious" reasons for the disparities which we have observed also fail to fit. There was no straightforward link between the potential supply of doctors and their role in the medical patchwork, either for individual families or sub-regions. Nominally, doctor-patient ratios were similar in most of the non-city areas of Lancashire, but, as we have seen, established doctors in the "west" appear to have reacted to limited effective demand by building up a client base further east. This situation was not the outcome of problems over affordability. Surveys of wealth distribution from the hearth tax onwards reveal no easy characterization of a rich "east" and poor "west". Indeed, by the later eighteenth century, parts of the northwest and southwest sub-regions were amongst the most wealthy areas in the north of England, let alone Lancashire. By contrast, parts of the east, and particularly towns such as Cowpe, were amongst the poorest parts of Lancashire. Ostensibly limited demand for doctoring services in the "west" probably had little to do with the nominal ability to pay, and in any case it is certainly true that all of the families cited thus far would have had little difficulty in either affording or finding formal medical practitioners had they wanted them. ${ }^{66}$

\footnotetext{
${ }^{64}$ Harley, op. cit., note 37 above, and D

Harley, 'Medical metaphors in English moral theology 1560-1660', J. Hist. Med., 1993, 48: 396-435.

${ }^{65}$ See LRO: DDSc/150/2, 'Commonplace book'.

${ }^{66}$ See Phillips and Smith, op. cit., note 38 above. Our thanks to Nigel Morgan for allowing
}

\author{
us to peruse his attempts to map wealth \\ distributions in early modern Lancashire. As an \\ extension of this point, it is clear that the \\ presence or absence of an urban culture is not a \\ predictive indicator of the way in which the \\ medical landscape was constructed within and \\ between sub-regions.
}




\section{Steven King and Alan Weaver}

More detailed investigation of the family and estate collections in Lancashire will be required before a rounded and sophisticated explanation can be developed. ${ }^{67}$ In particular, it would be desirable in the longer term to control for the lifecycle stage of both doctors and their patients in tracing the structure of the medical jigsaw. It would also be useful to reconcile apparent attitudes towards medicine and a range of other variables such as gender, family structure, landholding, and previous demographic record. Such perspectives will spring from further work. In the meantime, we might tentatively suggest that these apparent sub-regional characteristics reflect important differences in the way people from middling families perceived and valued health and ill-health, and in the deeprooted cultural traditions through which medicine was mediated. In the broadly conceived "west" an enduring suspicion of formal medicine and a belief in either doing nothing or undertaking self-dosing in response to illness, may have reflected a wider and stronger "folk-style" of life. There may also be a case for suggesting that relative insularity, intense local allegiances, and many more local dialect forms than in other areas of the county, bolstered these perspectives on health. Even amongst the middling families considered here, poor literacy was common when compared with families in the broadly conceived "east". And while it is a popular myth that the people of Rossendale in east Lancashire were unreceptive to new ideas and keen to preserve long-held traditions and superstitions, in practice almost all surveys of folk tales and superstitions in the county point to their greater longevity in the "west" broadly defined ${ }^{68}$ In the east, southeast and northeast, industrial concentration, proximity to Yorkshire, the rapid improvement of the road system in the late eighteenth century, and the early breakdown of core traditions and superstitions in the face of sustained in-migration from outside the sub-regions, fostered a much more open and less self-reliant society, and perhaps one more in touch with the tenets of fashion than the rest of the county. It may be for this reason that newspaper circulation figures in the "east" far outstripped those of the "west", even where we control for socio-economic structure. Here, and in the northeast of Lancashire in particular, families were

\footnotetext{
${ }^{67}$ It may be, for instance, that differences in the "publicness" of dying in different areas plays a part in what we see. In southwest Lancashire, many middling families would have followed the very public experiences of Charles Dickonson of Scarisbrick who, despite an income of $£ 60,000$ per year and the attentions of some of the best doctors, died a long and painful death.

${ }^{68}$ See, for instance, J Hobson, Lancashire folk-tales and superstitions, London, Longman, 1964. Crucially, northwest, central and southwest Lancashire were subject to much more moderate migration flows from outside the collective sub-regional context than were areas of the "east". In 'Migration networks in
}

\author{
Lancashire', in D Ebeling and S A King (eds), \\ Community, locality and life-cycle: migration \\ strategies in modern and early modern Europe, \\ Trier, Verlag für Regionalgeschichte, 2000, we \\ show that migration in "west" Lancashire was \\ more short distance and circular than in the \\ "east", and that those moving in the "west" \\ carried similar traditions with them in ways not \\ found, for instance, in Rossendale. Marriage \\ horizons were also narrower in the "west" than \\ the "east", even where we control for the \\ effects of the sea in coastal parishes. There \\ were, therefore, strong mechanisms for \\ continually reinforcing and recreating cultural \\ norms over time.
}


apparently tied into a very dynamic medical patchwork compared with that assembled elsewhere. In turn, a broad analysis of the activities of irregular practitioners and the contours of self-dosing goes some way to confirming both sub-regional variations in the medical patchwork, and the broad thrust of the explanation offered here.

\section{Irregular Practitioners and their Clientele}

The activities of irregular practitioners and their relationship to middling families, as opposed to artisans or the labouring poor, are extremely difficult to reconstruct, and only an outline can be offered here. As in Bath, eighteenth- and early nineteenth-century Lancashire newspapers contained innumerable advertisements for patent remedies, and for the services of "quacks" themselves. ${ }^{69}$ But, even in this, there are important sub-regional distinctions to be traced. The Manchester Guardian devoted up to one-fifth of its advertising space to patent remedies by the early nineteenth-century. We might have expected no less in a city context. ${ }^{70}$ However, newspapers in other parts of the broad "eastern" region also showed the same tendencies. Between 1810 and 1820 the Bolton Chronicle, the Bury Times, and the Clitheroe Mail devoted a collective 18 per cent of all advertising space to patent remedies. By contrast, none of the Preston newspapers reached anything like this density, even by the $1850 \mathrm{~s},{ }^{71}$ nor did newspapers in the prosperous northwest Lancashire towns of Kirkham and Poulton. It would be convenient to argue that these differences reflect the scale of urbanization in "east" Lancashire, but this is unlikely to be the major explanation. Northeast Lancashire looked very much like northwest Lancashire in terms of population densities and the patchy nature of the transport infrastructure, but quacks were apparently more active in the former than in the latter judging by the number of advertisements placed. Surviving handbills point in the same direction, suggesting that the broadly defined "eastern" sub-region, as well as the Manchester hinterlands, was very well served by the itinerant quack. ${ }^{72}$

\footnotetext{
${ }^{69} \mathrm{P}$ S Brown, 'Medicines advertised in eighteenth-century Bath newspapers', Med. Hist., 1976, 20: 152-68. Most of the medicalrelated advertisements in the Blackburn newspapers are reproduced in W Durham, Chronological notes on the history of the town and parish of Blackburn, Blackburn, THCL Books, 1988, where the activities of the most famous Lancashire quack, Alfred Crompton of Bury, can also be traced.

${ }^{70}$ Porter, op. cit., note 2 above.
}

\footnotetext{
${ }^{71}$ Though it is clear from chemists' bills for the Hesketh family that there could be an avid appetite for pills and potions on the part of some "west" Lancashire families. LRO: DDHe/62/114, 'Account of medicines from Chemists $\mathrm{H}$. Armstrong'.

${ }_{72}$ As one example of many, see BRO: ZZ 238/ 1/175/4, 'Advertisement by Jane Butter for books, instruments and patent medicines'. Substantial collections of flyers and other handbills can be found in Chetham's Library.
} 


\section{Steven King and Alan Weaver}

Much more work needs to be done on quack culture in the county, especially since we can be relatively confident that the middling families which form the focus of this article would have resorted to such sources of medical aid. Indeed, the density of advertising which we have highlighted could not have been aimed at the labouring classes alone. What we can be less certain about is the degree to which middling families in the different sub-regions had contact with informal practitioners who undertook "medicine" as a sideline to other activities and who were not in strict terms "quacks". Since some of these informal practitioners could claim to have been consulted by royalty, it seems likely that they would have been part and parcel of the medical landscape for at least some middling families. However, reconstructing their practice, their clientele and their place in middling perceptions of health and ill-health is difficult. As a broad generalization, based upon much laborious and unproductive searching through family accounts not reported here, it seems clear that belief in, and use of, informal practitioners reflects very strongly the sub-regional divisions which we have observed in the character of doctoring and the role of the doctor in wider Lancashire society. In so far as can be judged, there were more, and more active, informal practitioners in the sub-regions of the "east" of the county than in the subregions of the "west", emphasizing the dynamic medical culture of the former area. $^{73}$

Thus, in 1778 an account of a trial for murder in Clitheroe, northeast Lancashire, saw three men indicted for the killing of a butcher visiting the town to attend a local fair. One was a victualler, one a butcher and one was called Doctor Herd, butcher. A close reading of the depositions in the case reveals that this was Richard Herd, owner of a town-centre shop and a plot of 14 acres and resident in the town of Clitheroe for over two decades. The medical credentials of this man are obscure. The court recorder and the lawyers in the case consistently made a distinction between the titles they gave to the surgeons who appeared as witnesses and the "doctor" who appeared as a defendant. His character references suggest that he was a much respected informal practitioner with a wide acquaintance in Clitheroe, even among middling families. ${ }^{74}$ We know rather more about other east Lancashire irregulars. In the parish of Rochdale, the Taylor family were known as the "Whitworth doctors" and practised medicine alongside smithying. This was regularized into dedicated doctoring only in the nineteenth century, and they were sufficiently widely known to attract attention from prominent visitors to Lancashire during the

\footnotetext{
${ }^{73}$ Digby, op. cit., note 6 above, notes a complementarity between regular and informal practitioners in other rural areas.

${ }^{74}$ LRO: DDPr/60/2, 'Trial at large, 1778'. See also C Lawrence, 'Ornate physicians and learned artisans', in W F Bynum and R Porter (eds), William Hunter and the eighteenth-century
}

medical world, Cambridge University Press, 1985, pp. 79-106, and M C Versluysen, 'Old wives' tales? Women healers in English history', in C Davies (ed.), Rewriting nursing history, London, Academic Press, 1980, pp. 189-97. 
eighteenth and early nineteenth centuries. ${ }^{75}$ Both the Whitacker family of Clitheroe and the Heywood family of Bolton made use of the services of the Whitworth doctors. The Harrison family, of rural Cliviger in east Lancashire, were less famous than the Whitworth doctors, but could claim members of the Towneley family, the Whitackers, and even Robert Owen as among those whom they treated, or corresponded with. ${ }^{76}$

By contrast, there appear to have been few families comparable to the Whitworths or Harrisons in the sub-regions of "west" Lancashire. "Dr" James of Lancaster and "Dr" Harvey of Wigan were certainly informal practitioners, and both attained local celebrity in the 1790s. However, this was as a result of treating specific groups of the poor, seamen and miners respectively, and there is no evidence of connection with middling families. ${ }^{77}$ While more work needs to be done on the subject than has been possible for this article, the limited information which we have suggests that in northwest, central and southwest Lancashire, irregular practitioners were more irregular and more class specific in whom they treated, than was the case in the broadly conceived "east". As the experience of the Blundells, Ecclestons and others shows, in these western subregions it was more common for middling families to doctor the locality than to turn to irregular practitioners themselves. Such conclusions highlight the importance of reconstructing the scope and character of self-dosing in the different sub-regions, and of locating such practices within the perceptions of health, illhealth and "medicine" held by middling families.

\section{Self-Medication}

Reconstructing the landscape of self-medication is full of pitfalls. Commonplace books provide a useful potential perspective on this issue, but there are considerable ambiguities over how medical historians should interpret the self-dosing recipes which appear in them, and over the significance of the fact that such records were kept in the first place. ${ }^{78}$ One could argue, for instance, that the medical recipes to be found in commonplace books represent an uncertain accumulation of old wives' tales, concoctions fermented as a reaction to the changing nature of ill-health, and

\footnotetext{
${ }^{75} \mathrm{~J}$ L West, The Taylors of Lancashire: bonesetters and doctors 1750-1890, Worsley, Townson, 1977. Also C B Andrews, The Torrington diaries, containing the tours through England and Wales of Hon John Byng, later the Viscount Torrington, 1781-94, London, Methuen, 1970.

${ }^{76}$ Rawtenstall Library, 'Harrison collection'.

${ }^{77}$ See S A King, 'Preaching parsimony: attitudes to the sick poor in Lancashire 1700-1830' (forthcoming, 2000).
}

\footnotetext{
${ }^{78}$ There are no conventions for the analysis of commonplace books. For initial attempts see Lane, op. cit., note 11 above, also, Chamberlain, op. cit., note 10 above, and Porter and Porter, op. cit., note 21 above. The latter work traces a "grapevine" of self-dosing information and a "standard repertoire" of cures which was hardly undermined by a vigorous medical market-place before 1800 .
} 


\section{Steven King and Alan Weaver}

"real" cures borrowed from professional doctors. ${ }^{79}$ Alternatively, commonplace books and their cures may have been influenced by a publishing revolution which saw books like Domestic medicine, the Compleat servant maid, Wesley's Primitive physick and a variety of other health manuals and disease descriptions achieve wide circulation. ${ }^{80}$ Such almanacs and manuals certainly found their way into the libraries of Lancashire families who also kept commonplace books, and the Lancashire mechanic Benjamin Shaw copied large numbers of recipes into his own commonplace book. $^{81}$ Eighteenth- and nineteenth-century magazines also took an interest in medicine, and may have opened up the best and worst of practices to a growing army of medical consumers. They certainly expanded the vocabulary of disease and treatment used by lay families, and establishing the date and provenance of what appears in commonplace books is thus potentially difficult. Equally, we might question the utility of the remedies, and whether the very existence of a commonplace book represents an attempt to build up a core of useful medical knowledge or simply idle collecting without a notion of usage. There is plenty of support for the latter idea. Joan Lane talks of "an amazing catalogue of bizarre self-help cures", for instance, and there are many examples of families and friendship groups idly exchanging fashionable or unusual medical "knowledge". ${ }^{82}$ The tendency for the keepers of commonplace books to record lay remedies, quack recipes, and the cures of formal practitioners side-by-side, together with a whole range of sayings, recipes for food, and other items of general interest, adds to the difficulty of interpreting what they can tell us and what they cannot.

\footnotetext{
${ }^{79}$ The chronology of the different recipes can be uncertain. Even where it is clear, the significance to be attached to the fact that, say, more recipes for cure of toothache or bronchial illnesses appear in the late eighteenth century is not. The presence of such recipes might reflect the effect of changing diets, air and water pollution on underlying health in terms of the frequency of toothache, colds, coughs, and asthma, or it might not. Cures for these sorts of complaints litter the estate collections of Lancashire. On bowel movements, see LRO: DDGr M/1/16, 'Receipt for bilious habits or affectation of the system' (1760) or LRO: DDX 576/2, 'Recipe to avoid flatulence' (1750). Cures for toothache varied from chewing ginger roots through dried and powdered woodlouse to mastic gum. See LRO: DDX 576/14, 'Cure for toothache'. Cures for drowning also start to appear in commonplace books from the $1750 \mathrm{~s}$, perhaps reflecting increased risks of water accidents in canals, river cuttings and mill ponds. See LRO DDGr/M/1-6, 'Recipe book' for good examples. The survival of a comprehensive set of medical lecture notes from the younger son of a prominent Lancashire family which kept a commonplace book is testimony to another source of such recipes. See LRO: DDb/83/2-9, 'Medical lecture notes'. For a
}

review of the context of these notes see $\mathrm{N} \mathrm{C}$ Hultin, 'The testimony of our senses: William Heberden's lectures upon materia medica of 1743', Pharm. Hist., 1990, 32: 95-110.

${ }^{80}$ See R Porter, 'Spreading medical enlightenment: the popularization of medicine in Georgian England and its paradoxes', in R Porter (ed.), The popularisation of medicine, 1650-1850, London, Routledge, 1992, pp. 215-31, and M Fissell, 'Readers, texts and contexts: vernacular medical works in early modern England', in ibid., pp. 72-96.

${ }^{81}$ See, for instance, LRO: DDMc/7/54, 'Account of books from Dr and Mrs Hodgson' and LRO: DDIn 14/57, 'Letters and account of books purchased', also, A G Crosby, The family records of Benjamin Shaw mechanic of Dent, Dolphinholme and Preston, 1772-1841, Manchester University Press, 1991. The Shaw records can be found in LRO: DDx/1554. For other examples, see LRO: DDAr/334, 'Cure for gravel copied from the Dublin Journal 1769', also, H J Cook, 'Good advice and little medicine: the professional authority of early modern English physicians', J. Br. Stud., 1994, 33: $1-31$.

${ }^{82}$ See Lane, op. cit., note 11 above, p. 241. 
However, to pass over these records because they are difficult to decode risks missing a vital component of the medical scene, particularly in Lancashire. Middling families, spread over all the sub-regions identified here, appear to have taken their commonplace books very seriously. Indeed, some of the "cures" certainly had an implicit or explicit monetary value, and were not simply collected idly or when the opportunity arose. In 1750, Captain Roger Dewhurst of the township of Halliwell in southeast Lancashire gave a pointer puppy to a neighbour. In return he was to receive a recipe "for taking down an accidental swelling made of origanum and turpentine". The fact that Dewhurst was willing to part with a puppy for which he might have got upwards of $£ 4$ had he chosen to sell it, suggests that he was doing more than simply idle collecting. ${ }^{83}$ Thomas Eccleston also paid for a "Recipe for red powder" in 1759, a universal recipe good for "the extremity of smallpox and measles taken early ... plague or fever or surfeit, or for women lying in child bed and for children who have worms" ${ }^{84}$ The Dickonsons paid two shillings for a similar recipe in 1792, and then sold it to other members of the locality. ${ }^{85}$ Journals and account books kept by the Parker family suggest that they went one stage further during the 1770s and 1780s. Not only did they purchase recipes, they also used them to brew medicines, which they then sold.$^{86}$ It is, of course, impossible to tell whether these sorts of recipe originally came from a doctor, irregular, apothecary, medical manual, or whether they were simply made up. However, in many respects the origin of the cure is less important than the fact that it changed hands for a consideration. This suggests that at least some Lancashire commonplace books were kept to provide a stock of useful medical knowledge, and occasional marginal notes indicate that some families really did try, test, and refine the cures which they recorded. ${ }^{87}$

A broad overview of surviving commonplace books in the main estate collections of Lancashire is thus an important element in reconstructing the regional and sub-regional medical landscape. This is a considerable undertaking, and we only have the space to report two key features which emerge from such an exercise. First, at the outset of the eighteenth century the range of problems for which "cures" were recorded was limited, but on the whole the recipes were surprisingly precise. A few examples will have to stand for many which we could have employed. Thus, in 1728 Francis Barton of Broughton in central Lancashire recorded the composition of a cure given to the Barton children for whooping cough. It involved a "handful" of house leek, boiled together with some brown sugar until the mixture had the consistency of syrup. The house leek was drawn off and pressed, with the juices and syrup mixed together to

\footnotetext{
${ }^{83}$ W D M Billington (ed.), Captain Dewhurst and his diary, Bolton, Bolton Chronicle, 1971.

${ }^{84}$ LRO: DDSc 127/2, 'Book of memoranda'.

${ }^{85}$ LRO: DDx/274, 'Papers of the Dickonson family'.
}

\footnotetext{
${ }^{86}$ LRO: DDb (Uncatalogued), 'Diaries'.

${ }^{87}$ More direct evidence of this sort of empiricism can be seen in the correspondence of the Shaw family of Wigan. See WRO: EHC54, 'Papers of the Shaw family'.
} 
form a tonic which was to be taken daily. ${ }^{88}$ William Scarah, of Poulton in northwest Lancashire, was constructing his commonplace book at around the same time, and his measuring of ingredients was more precise and more representative. His cure for a cough or whooping cough consisted of two pennyworth of milk, two pennyworth of sweet oil, two ounces of brown sugar, the yolk of an egg and one spoonful of rum mixed together. For dropsy he employed three pennyworth of horseradish (crushed), three pennyworth of camphor, three pennyworth of orange peel, a handful of watercress, a little bird lime, ashes, unflecked lime and four quarts of old ale, mixed and left to stand for twenty-four hours before drinking. ${ }^{89}$ Instead of imprecise dosages such as handfuls, he employed more objective monetary based measures. The Standish family also measured in terms of pennyworths at the outset of the eighteenth century. Such examples suggest a wide understanding of such measures, some degree of standardization, and an active market for ingredients even at this early date.

The second feature which emerges from a broad overview of commonplace books is that the mid-to-late eighteenth century was to mark a considerable expansion in the range of problems for which "cures" were recorded, a new interest in broad herbal cures, even more precise quantification, and the development of a wide "bank" of public knowledge on the intricacies of selfmedication. Again, a few examples must stand for many. Thus, in the 1730s Scarah's remedy for rheumatism consisted of one and a half drams of aloes, a handful of rhubarb powder, a dram of ginger powder and three drops of oil of aniseed mixed in syrup, to be taken two to three times per day. ${ }^{90}$ In 1772 , a remedy employed for the same complaint by John Dickonson used camomile, goosegrass and St John's wort, powdered and mixed with strong alcohol. The ingredients used here were more herbal than those of Scarah, and they were measured in terms of ounces rather than handfuls or drops. ${ }^{91}$ Similarly, the Dickonson cure for fever in the 1780s comprised two ounces of elm bark, quarter of an ounce of salt of wormwood and quarter of an ounce of smallroot, powdered and mixed with water to be taken three times per day. This compares with Scarah, who five decades earlier used a handful of camomile and a handful of rock alum boiled in water and to be taken every four hours, for the same complaint. ${ }^{92}$ A tendency to record more precise recipe and dosing requirements is not, of course, surprising. The flowering of prescription medicine and the publication of ever more precise self-help manuals did not pass Lancashire

\footnotetext{
${ }^{88}$ LRO DDx: 151/2, 'Francis Barton's book of disbursements'.

${ }^{89}$ See K Souter, Cure craft: traditional folk remedies and treatments from antiquity to the present day, Saffron Walden, Bry Books, 1995, p. 81, for the properties of these herbs. WRO: EHC54/M820, 'Scarah's commonplace book'.
}

\author{
${ }^{90}$ WRO: EHC54/M820, 'Scarah's \\ commonplace book'. \\ ${ }^{91}$ LRO: DDx/274, 'Papers of the Dickonson \\ family'. \\ ${ }^{92}$ See LRO: DDx/274 and WRO: EHC54/ \\ M820.
}


commonplace books by, as we have established. ${ }^{93}$ Perhaps more important for our understanding of the medical landscape which middling families perceived is the greater concentration on herbs, and with it wider access to "cures". Thus, when the Walmsley family doctor wrote to George Walmsley in 1806 outlining a range of "country remedies which I like very much because they are very desirable, and I hope that you will gain some benefit from them" ${ }^{94}$ he assumed that such recipes were familiar, that the Walmsleys had herbal knowledge, and that herbs and other ingredients (from both home and overseas) could be acquired easily and cheaply at need. He was probably right. Support for herbal lore in the county developed consistently in the eighteenth century. The March 1741 issue of the Manchester Magazine contained a guide to several books on herbs, one advertising detailed descriptions and locations of 500 "of the most useful plants used in the practice of Physik". ${ }^{95}$ Artisan botany also appears to have developed a tenacious hold in many areas, and artisan botanists and their families increasingly supplemented wise men and women who understood the properties of different herbs. ${ }^{96}$ In turn, there is little persuasive evidence that access to herbs had declined notwithstanding urbanization and population growth in the county. The physical area of cities and towns was limited until well into the nineteenth century, and the countryside lay within easy reach. If anything, the impact of industrialization and urbanization may have improved access to herbs by stimulating a number of specialist herb growers and purveyors in both urban and rural areas. ${ }^{97}$ Outside the cities and towns, the Reverend Dr Bateman notes clearly that herbs and other ingredients for home remedies could be found in almost all hedgerows. ${ }^{98}$

Much more could be said about middling commonplace books and the families who kept them. However, what becomes abundantly clear is that in all the Lancashire sub-regions self-medication was a central part of the middling medical practice, and one increasingly clothed in the trappings of accepted orthodoxy. Yet this is not the end of the story. The role of these "cures" differed between areas. In the sub-regions of "east" Lancashire our cumulative evidence suggests that increasingly sophisticated self-dosing simply contributed to an already dense medical provision centring on regular and informal medical personnel. A brief family history can illustrate this point. The Parker family from "east" Lancashire was tended by the same doctor, William St Claire, for many years. Between the early 1770s when he first made his appearance, and 1802, when he wrote a letter of condolence to the Parkers on the occasion of the death of their eldest son, his methods changed little-leeches,

\footnotetext{
${ }^{93}$ See for instance the commonplace books of the Cavendish family; LRO: DDCa/17, 'Cures'.

${ }^{94}$ LRO: DDWa, 'Unlisted correspondence, 1806 .

${ }^{95}$ Manchester Central Library: Manchester Magazine, 1741.
} 


\section{Steven King and Alan Weaver}

blistering, diet and air were the central elements in his kit bag. Prior to, and alongside, the services of St Claire the family also made use of local apothecaries wherever they happened to be. ${ }^{99}$ When Thomas Parker took up the reins of the family from the early 1790s, however, and as St Claire himself became older, a new and sophisticated herbal self-help regime began which ran alongside the activities of formal medical men. Between 1793 and his death in 1802, probably from malaria, the eldest son was fitfully ill. While St Claire applied his traditional methods, the family subjected the son to a plethora of medical treatments, many of them centring on the use of the herb meadow saffron as a remedy for persistent fever. When, in October 1793, St Claire wrote to tell Thomas Parker senior that his son was "out of danger" it was perhaps the herbal self-help remedies applied by different members of the family which had provided the real benefit, not the services of the doctor himself. ${ }^{100}$ St Claire was almost a member of the Parker family, but in the dynamic medical environment of "east" Lancashire self-dosing, from whatever source guidance was drawn, was still very important.

There is nothing particularly surprising in this story. In common with many other families at national level the medical life of the Parkers was held in many hands - doctors, quacks and their own. In this sense, the Parkers and most other "east" Lancashire middling families would not look out of place if transplanted to any English region. In the sub-regions of "west" Lancashire, mortal or surgical illness apart, commonplace books must have been a mainstay of medical treatment, given the failure of doctors and patients to develop the character and density of connection that they appear to have formed elsewhere. The experiences of Doctors Loxham and St Claire provide convincing evidence that nominal demand was not converted to effective demand for medical men, and a much stronger emphasis on self-help in these sub-regions emerges convincingly from a reading of voluminous family papers. Once again, a brief family history will help to elaborate this point. The Gillow family of Singleton in northwest Lancashire called on Richard Loxham on three occasions between 1767 and 1772. In two instances, he treated servants involved in serious accidents, and only once did he attend a member of the Gillow family itself. On this occasion he cut out an advanced cancerous lump on the face of George Gillow. Loxham was apparently the only doctor whom the family called, and serious illness contracted by the Gillow children in the form of measles and whooping cough was borne with resignation and herbal remedies. Fevers and accidents suffered by George Gillow were dealt with in a similar way, and Loxham was not even called for follow up visits after his surgery. It is no surprise to find family correspondence littered with medical advice and recipes, among them numerous cures

\footnotetext{
${ }^{99}$ The tuition accounts for Thomas Parker at Emmanuel College, Cambridge, record that he had occasion to visit the apothecary at least once and usually more times a year between 1740 and 1743. See: LRO DDb 74/10, 'Tuition accounts for Thomas Parker'.
} 
for cancer. ${ }^{101}$ These important differences in sub-regional medical outlooks certainly highlight the need for more regional studies of this sort, as well as more work on Lancashire itself.

\section{Conclusion}

This article makes no claims to offer definitive conclusions. We have presented just a part of the evidence which permits the reconstruction of the medical landscape as it would have looked to middling consumers. Over and above this limitation, key weaknesses remain. The nature of source survival means that in any case we have relatively few examples with which to characterize the medical outlook of wide subregions. How representative the experiences of the doctors and middling families reviewed here actually were is a question which remains unanswered and unanswerable. Even if our examples can claim representativeness, implying motivations and outlook from sources such as letters, account books, commonplace books and diaries will always be subject to a degree of interpretation. And, of course, there is a danger that in trying to argue for sub-regional divisions all we are in fact doing is trying to shape the medical landscape into an arbitrarily defined set of spatial boxes. Ultimately, the answers to these potential criticisms will seem tame. We can work only with the sources which are accessible, and in this sense the survey conducted here is more complete than for any other region in current medical historiography. In undertaking the survey, we have been cautious in the use of evidence and have sought to corroborate interpretations which we have placed upon ambiguous documents such as letters. And while our sub-regional boundaries may be slightly misplaced, the existence of the sub-regions themselves is not to be disputed.

Against this backdrop, it would not be too much to claim that this article has done what it set out to do. Regional studies do have a value, both as an exercise in methodology, and in terms of what they can tell us about the validity of the "national" trends which dominate the conceptual framework within which medical historiography is located. Some of the potential gaps in our knowledge of these trends can be filled. We have seen, for instance, the development of a doctor-sensitive culture in "east" Lancashire which has an identity over and above simple doctorpatient relationships. We have also gained more knowledge about the nature of irregular practice in Lancashire, about the value of commonplace books, and about the changing character and role of self-medication. Yet we can go even further and suggest that we have barely scratched the surface of the English medical landscape in the eighteenth and nineteenth centuries. Conventional ways of "measuring" this panorama, in terms of the absolute number of doctors or the level of doctor-patient ratios, provide at best a partial guide to the contours of local medical life. At worst, they can be downright misleading. Meanwhile, within the framework of the subregional medical outlooks which we have identified, there is only a limited place for the rational consumer, for market clearing in the medical profession, and for a model

\footnotetext{
${ }^{101}$ The Gillow archive is held on microfilm at Lancaster University Library.
} 


\section{Steven King and Alan Weaver}

of medical progress. Structures of culture, custom, literacy, migration and regional identity shaped the medical scene in ways which we have only just begun to recognize. For Lancashire at least, a new conceptual framework is needed-one which places choice before constraint, and regional and sub-regional distinctiveness ahead of national trends to which all places eventually conform. This may be the focus of later work. 